\title{
Cosmolaelaps keni a Polyphagous Predatory Mite on Various Insect and Mite Species (Acari: Laelapidae)
}

\author{
F. M. MOMEN ${ }^{1 *}$, A. S. METWALLY ${ }^{2}$, A. K. NASR ${ }^{1}$, M. GESRAHA ${ }^{1}$, \\ Y. A. MAHMOUD ${ }^{1}$ and K. H. M. SALEH ${ }^{1}$ \\ ${ }^{1}$ Pests and Plant Protection Department, National Research Centre (NRC), \\ 31 El-Bouhoth Street, 12311 Dokki, Cairo, Egypt \\ ${ }^{2}$ Department of Agricultural Zoology and Nematology, Faculty of Agriculture, \\ Al-Azhar University, Cairo, Egypt
}

(Received: 19 December 2017; accepted: 19 January 2018)

\begin{abstract}
The predatory mite Cosmolaelaps keni is a native laelapid mite in Egypt. Development and adult longevity durations as well as fecundity of $C$. keni reared on five types of prey, Bactrocera zonata, Spodoptera littoralis and Corcyra cephalonica eggs (as insects prey), Aceria dioscoridis and Caloglyphus rodriguez (as mites prey) were determined under laboratory conditions. Cosmolaelaps keni was able to feed, develop and sustain oviposition on all examined insect and mite species. The mean developmental period of $C$. keni on B. zonata and S. littoralis eggs was significantly shorter than those fed C. cephalonica eggs and both mite species. Deutonymphs of $C$. keni were consumed similar number of insect eggs, while during the oviposition period, more $B$. zonata eggs were consumed. A diet of $C$. rodriguez provided the shortest oviposition period and longevity, while $C$. cephalonica eggs showed the longest period in this respect. During the oviposition period, preying on $B$. zonata and $C$. cephalonica eggs gave the highest fecundity rates for the predatory mite compared to $S$. littoralis and $C$. rodriguez. The sex ratio of $C$. keni progeny was in female-biased. Bactrocera zonata eggs as a prey gave the highest rate of oviposition as shown by the maximum fertility, net reproductive rate and gross reproductive rate as well as the shortest generation time compared to other tested prey; therefore B. zonata eggs were appropriate factitious prey for oviposition and mass rearing of the predatory mite $C$. keni.
\end{abstract}

Keywords: Cosmolaelaps keni, polyphagous predator, biological control, factitious prey.

The family Laelapidae consists of predators of invertebrate soil organisms (Beaulieu, 2009). Some species of laelapid mites proved that they may play an important role in biological control of eggs and larvae of micro-arthropods/nematodes (Walter and Proctor, 1999).

For example, Cosmolaelaps simplex Berlese and Cosmolaelaps qassimensis Fouly and Abdel-Baky are efficient biocontrol agents against the nematodes Tylenchulus semipenetrans (Cobb), Meloidogyne javanica Treub and M. incognita Chitwood as well as the acarid mites, Caloglyphus rodriguez Samsinak and Tyrophagus putrescentiae (Schrank) (Al-Rehiayani and Fouly, 2005; Fouly and Abdel-Baky, 2015). Moreira et al. (2015) designated the role of Cosmolaelaps jaboticabalensis Moreira, Klompen and Moraes in controlling Franklinella occidentalis (Pergande) under laboratory conditions.

\footnotetext{
* Corresponding author; e-mail: fatmomen@yahoo.com
} 
One of the main inhibitions for the applied use of augmentative biological control in the managements of mite/insect enemies is the high price of commercially produced natural enemy (De-Clercq et al., 1998). Providing only unnatural (factitious) prey for rearing predatory mites/insects may be more inexpensive than using the expensive one (natural prey). For example, unnatural prey increase the economic cost of marketable production systems as predators can be reared in bulk in a rearing component (Zhang, 2003).

Although there is ample literature of factitious and alternative food for phytoseiid predatory mites, no information is available for the suitability of these foods for Cosmolaelaps keni Hafez, El-Badry and Nasr. For example, the eriophyid mite, Aceria dioscoridis (Soliman and Abou-awad) (Acari: Eriophyidae) infested the weed banker plant Pluchea dioscoridis L. was performed as a perfect unnatural prey for various predatory mites of the family Ascidae and Phytoseiidae (Momen et al., 2011, 2014).

A few astigmatine species have been found to be suitable factitious food for several rhodacarid, ascid, phytoseiid and laelapid predatory mites (Castilho et al., 2009; Moreira et al., 2015; Massaro et al., 2016; Barbosa and de Moraes, 2016). In (2003), van Lenteren designated that the egg stage of few lepidopteran species have been used as factitious prey by some commercial insectaries to produce generalist predators van Lenteren, 2003. Many lepidopterans can be reared effectively on diets that are devoid of living plant materials (Riddick, 2009). Several other species can be produced simply on relatively cheap food, such as wheat flour or grains. Eggs of Ephestia kuehniella Zeller (Lepidoptera: Pyralidae) was proved to be an excellent factitious food for several predatory mites of the family Phytoseiidae and Laelapidae (Momen and El-Laithy, 2007; Vangansbeke et al., 2014; Moreira et al., 2015; Navarro-Campos et al., 2016).

As the predators and their factitious prey do not coexist in a natural habitat, it is important to test and acknowledge the values of the predator-prey relationship in this artificially created system. Grenier and De Clercq (2003) pointed out that, whereas measures of development and reproduction of an arthropod natural enemy on an unnatural diet are revealing for the value of the diet for rearing purposes, the vital quality parameter of an artificially reared natural enemy is its predation efficacy.

Here we presume that $C$. keni can feed, oviposited and increases in great numbers on various factitious prey, then, selection of the best performed one on which it can be reared easily to support its populations in augmentative release programs. So, the scope of this investigation was to evaluate the potential of $C$. cepalonica, S. littoralis and B. zonata eggs and C.rodriguez and A. dioscoridis as factitious prey sources for rearing the predatory mite C. keni.

\section{Materials and Methods}

\section{Rearing and experimental unit}

Stock colony of C. keni was obtained from soil associated with very wet roots of tomato plants (Lycopersicom esculentum) L. at Tanta Province, Gharbia Governorate, Egypt during February 2015. Cosmolaelaps keni was cultured on B. zonata eggs in plastic cells ( $2.5 \mathrm{~cm}$ in diameter and $2 \mathrm{~cm}$ in depth) containing a floor of plaster of Paris and charcoal (mixed in a $9: 1$ ratio) were used. For biological experiments, small plastic cells $(1.0 \mathrm{~cm}$ in diameter and $0.8 \mathrm{~cm}$ in depth) were used. A large heavy glass cover was used for each 
cell to prevent mites from escaping. Activated plaster floor kept humid by daily addition of water. Bactrocera zonata eggs were added daily to the predator as the sole food. Feeding experiments were conducted in the laboratory at $28 \pm 1{ }^{\circ} \mathrm{C}$ and $70-75 \%$ relative humidity (RH). The newly deposited eggs by female's $C$. keni, were singly removed from cultures in large cells to the small one for different biological tests.

\section{Prey types tested}

Five different factitious prey belonging to two broad categories (insects and mites species) were evaluated for their effects on development, survival and fecundity as well as life table parameters.

Bactrocera zonata and C. cephalonica eggs were obtained in accordance with the methods of Nasr et al. (2015) and Momen et al. (2016). Egg batches of S. littoralis were collected from the farm of the Faculty of Agriculture, Cairo University, and transferred (on small pieces of the host leaf) to rearing arenas for feeding experiments. The grass eriophyid mite, A. dioscoridis was obtained from galls of the weed ploughman's spikenard $P$. dioscoridi grown year-round and being found in several agro-ecosystems in Cairo such as tomato and eggplants; while the acarid mite $C$. rodiguez collected from wheat stores near Tanta Province and cultured with a mixture of $50 \%$ yeast and $50 \%$ wheat germ. All handling of insect eggs and mites was performed with a very fine moistened squirrel-hair brush.

\section{Life history studies and demographic parameters}

A newly laid single egg of $C$. keni was transferred to small experimental cell. For each prey, a total 25-30 eggs were used. Each larva and subsequent stages of the predatory mite was provided with additional insect eggs/mite species (more than that consumed daily). The number of consumed insect eggs and mites was calculated daily. Fresh insect eggs and mites were offered daily.

The developmental periods of different stages of $C$. keni were recorded every $12 \mathrm{~h}$. Newly emerged females of the predator were allowed to copulate with males. The experimental cells were examined every $24 \mathrm{~h}$ to determine the duration of various physiological periods, daily consumption and oviposition rates as well as sex ratio of the progeny being calculated also. All experiments were conducted under laboratory conditions $\left(28 \pm 1{ }^{\circ} \mathrm{C}\right.$ and $70-75 \% \mathrm{RH})$.

\section{Statistical analysis and life table}

The mean duration of each stage, also total immature phases duration and all physiological stages, longevity and fecundity on various prey were submitted to analyses of variance using One Way ANOVA and means compared by Tukey HSD $(P=0.05$ level) using SPSS computer program. Data were fitted with the assumption of normality, not transformed, and differences were compared for the predator female between all prey species. Fertility life table (Birch, 1948) was constructed for the predator reared on each prey and calculated by using the computer program "TWOSEX-MSChart" for life table analysis by Huang and Chi (2013). 


\section{Results}

Influence of insects and mites prey on the life history of Cosmolaelaps keni

Cosmolaelaps keni larva is a non-feeding stage. The durations of larval stage were similar on the various prey species (Table 1). The developmental time of protonymphs and deutonymphs was significantly influenced by prey. Female deutonymphs reared on B. zonata eggs took significantly less time to develop to adulthood than those fed on other prey (Table 1). Total developmental time (from egg to adult) of females offered C. rodriguez or $C$. cephalonica eggs was significantly longer, followed by $A$. dioscorides than on $S$. littoralis and/or B. zonatae eggs $(\mathrm{F} 4,84=36.890, P=0.0001)$ (Fig. 1). The consumption rates of $C$. keni females are summarized in (Table 2). Prey type significantly affected the predation of females. Protonymphs and deutonymphs of $C$. keni were consumed similar amount of insect eggs, while they consumed about 25.94 individuals of $C$. rodriguez to develop to adulthood (Table 2, Fig. 2). Prey significantly influenced the duration of the pre-oviposition and oviposition periods (Table 1). Females fed on B. zonata eggs had significantly shorter pre-oviposition period than those fed on other prey, but insignificant differences were observed when fed on $S$. littoralis eggs or C. rodriguez. Mean oviposition period and female longevity were statistically shorter on $C$. rodriguez (oviposition

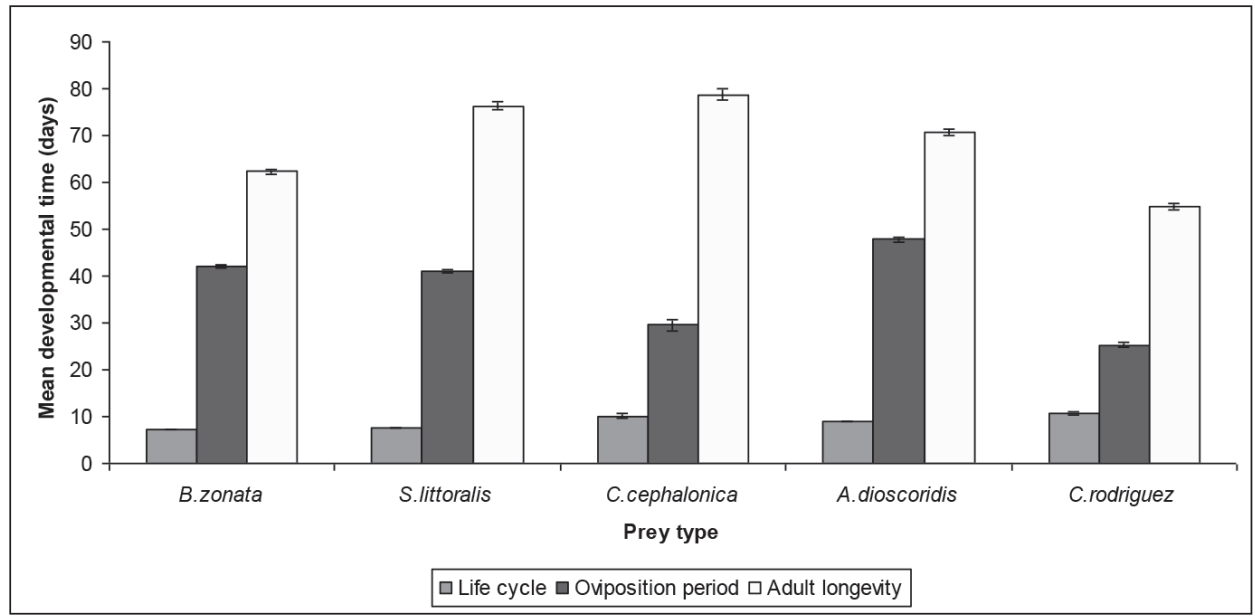

Fig. 1. Mean developmental and oviposition periods and female longevity of Cosmolaelaps keni fed various factious prey

period: $\mathrm{F} 4,84=368.865, P=0.0001$ and female longevity: $\mathrm{F} 4,84=139.164, P=0.0001$ ), whereas insignificant female longevity being noticed on $S$. littoralis and $C$. cephalonica eggs (Fig. 1). The post-oviposition period was statistically the same on B. zonata eggs and A. dioscorides but longer on $C$. cephalonica eggs $(\mathrm{F} 4,84=137.145, p=0.0001)$ (Table 1$)$. Among the insects prey, the consumption rate was significantly higher during the oviposition periods on B. zonata (176.83 eggs) followed by C. cephalonica (146.11eggs) and S. littoralis (135.44 eggs) $(\mathrm{F} 3,68=56.80, P=0.0001)$ (Table 2, Fig. 2). 


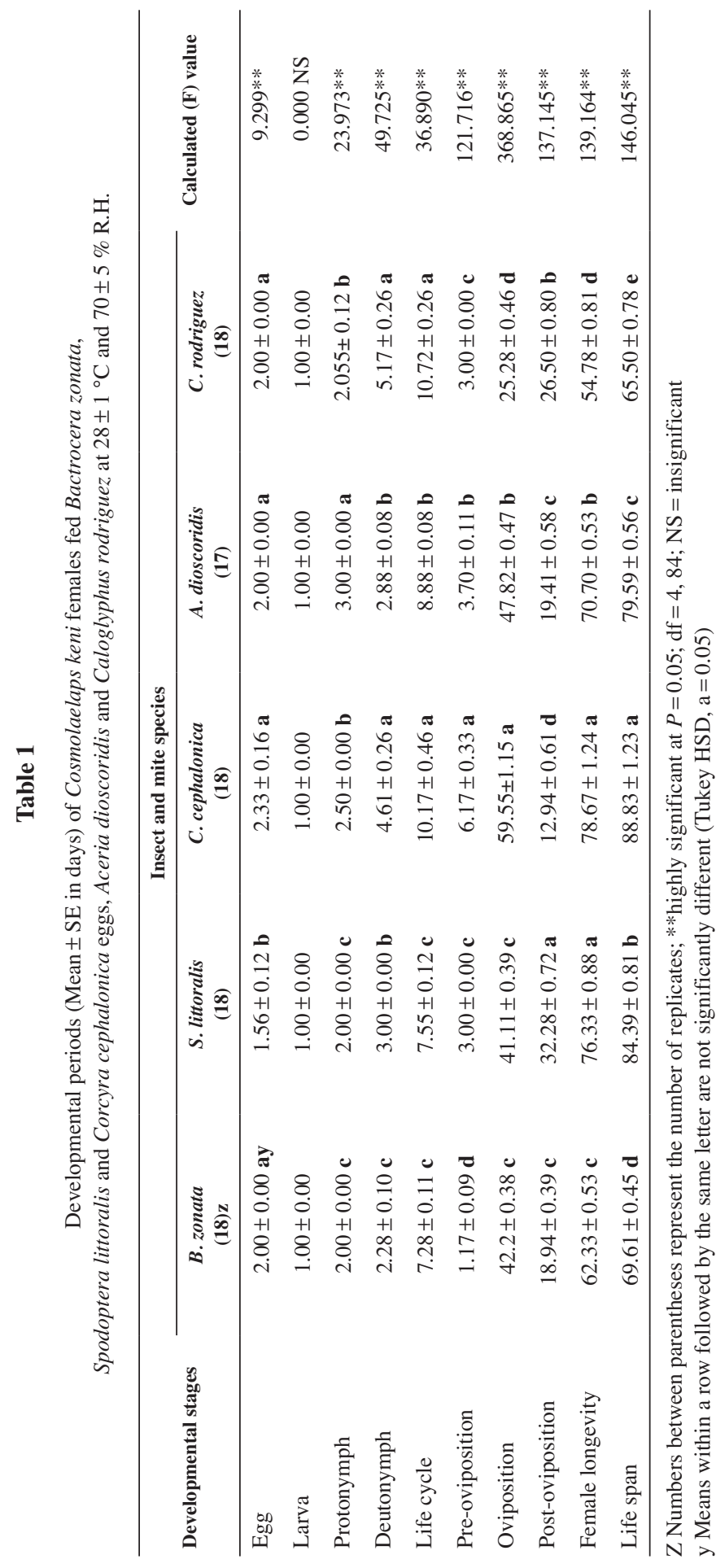




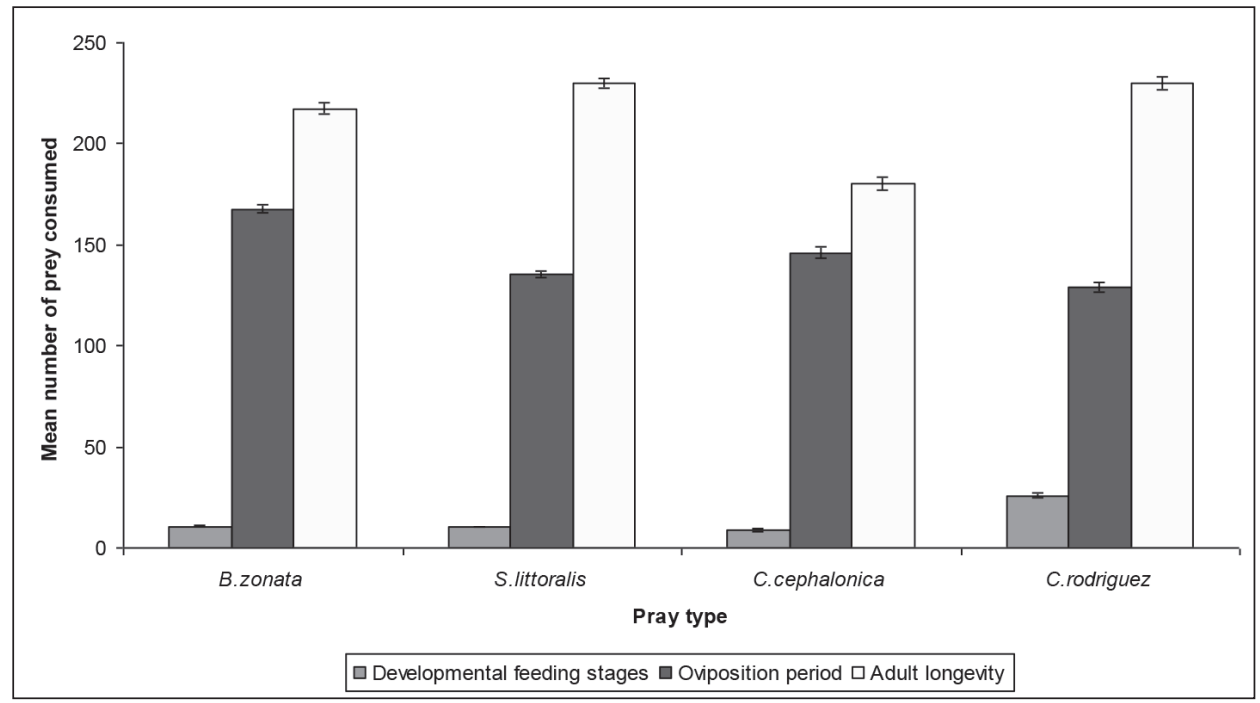

Fig. 2. Mean total consumption rate of Cosmolaelaps keni during developmental and oviposition periods and female longevity when fed various factious prey

Table 2

Total numbers (Mean \pm SE) of consumed Bactrocera zonata, Spodoptera littoralis and Corcyra cephalonica eggs and Caloglyphus rodriguez during the developmental periods and adult longevity of the predatory mite Cosmolaelaps keni females at $28 \pm 1{ }^{\circ} \mathrm{C}$ and $70 \pm 5 \%$ R.H.

\begin{tabular}{|c|c|c|c|c|c|}
\hline \multirow{3}{*}{$\begin{array}{l}\text { Female stages } \\
\text { Larva }\end{array}$} & \multicolumn{4}{|c|}{ Insect and mite species } & \multirow{2}{*}{$\begin{array}{c}\text { Calculated } \\
\text { (F) value }\end{array}$} \\
\hline & B. zonata $(18) \mathrm{z}$ & S. littoralis (18) & $\begin{array}{c}\text { C. cephalonica } \\
\text { (18) }\end{array}$ & C. rodriguez (18) & \\
\hline & \multicolumn{5}{|c|}{ Non-feeding stage } \\
\hline Protonymph & $3.55 \pm 0.12 \mathbf{b y}$ & $3.00 \pm 0.00 \mathbf{b}$ & $2.17 \pm 0.20 \mathbf{c}$ & $6.22 \pm 0.42 \mathbf{a}$ & $52.19 * *$ \\
\hline Deutonymph & $6.89 \pm 0.38 \mathbf{b}$ & $7.61 \pm 0.24 \mathbf{b}$ & $6.50 \pm 0.43 \mathbf{b}$ & $19.72 \pm 1.04 \mathbf{a}$ & $110.11^{* *}$ \\
\hline $\begin{array}{l}\text { Feeding stages } \\
\text { consumption }\end{array}$ & $10.44 \pm 0.38 \mathbf{b}$ & $10.51 \pm 0.24 \mathbf{b}$ & $8.72 \pm 0.58 \mathbf{b}$ & $25.94 \pm 1.09 \mathbf{a}$ & $150.03 * *$ \\
\hline Pre-oviposition & $4.78 \pm 0.38 \mathbf{d}$ & $10.22 \pm 0.20 \mathbf{c}$ & $14.00 \pm 0.95 \mathbf{b}$ & $16.67 \pm 0.19 \mathbf{a}$ & $94.51 * *$ \\
\hline Oviposition & $167.83 \pm 1.99 \mathbf{a}$ & $135.44 \pm 1.59 \mathrm{c}$ & $146.11 \pm 2.97 \mathbf{b}$ & $128.94 \pm 2.21 \mathrm{c}$ & $56.80 * *$ \\
\hline Post-oviposition & $44.72 \pm 1.13 \mathbf{b}$ & $83.83 \pm 1.76 \mathbf{a}$ & $20.17 \pm 0.87 \mathbf{c}$ & $84.72 \pm 2.72 \mathbf{a}$ & $317.85^{* *}$ \\
\hline Adult longevity & $217.33 \pm 2.70 \mathbf{b}$ & $230.00 \pm 2.42 \mathbf{a}$ & $180.28 \pm 3.38 \mathbf{c}$ & $230.22 \pm 3.21 \mathbf{a}$ & $63.74 * *$ \\
\hline
\end{tabular}

Z Numbers between parentheses represent the number of replicates; ** Highly significant at $P=0.05 ; \mathrm{df}=3,68$. y Means within a row followed by the same letter are not significantly different (Tukey HSD, a $=0.05$ ) 


\section{Influence of insects and mites prey on the female fecundity and demographic parameters}

Total fecundity was significantly influenced by different unnatural prey (Table 3 ). Results revealed that the mean total fecundity was significantly higher on $B$. zonata eggs (97.11 eggs/ female) followed by $C$. cephalonica eggs than for those maintained on $C$. rodriguez (37.06 eggs/female) or $S$. littoralis eggs (73.06 eggs/female) and $A$. dioscoridis (75.71 eggs/female) $(\mathrm{F} 4,84=2622.126, P=0.0001)$ (Table 3$)$. The sex ratio of the offspring determined by rearing the eggs deposited by the predator females to adulthood with each prey appeared in Table (3). The sex ratio of $C$. keni offspring was with a proportion of females ranging from 0.58 to $0.69 \%$.

Life-table parameters of $C$. keni on five prey species are presented in Table (3). There were significant differences among prey species for all parameters measured (Ro, $\mathrm{rm}, T, \lambda, \mathrm{GRR})(P<0.05)$. The results showed that the net reproductive rate $(\mathrm{Ro})$, intrinsic rate of natural increase $\left(\mathrm{r}_{\mathrm{m}}\right)$ finite rate of increase $(\lambda)$ and gross reproductive rate (GRR) were significantly highest on B. zonata eggs and lowest on $C$. rodriguez (Table 3 ). Generation time $(T)$ was significantly shorter for females offered B. zonata eggs versus the other prey.

\section{Discussion}

The present study revealed that there are significant differences in performance of the predatory mite towards five prey types. Different prey had notable effects on all valuable parameters of fertility life table and all calculated parameters (Ro, rm, $\lambda, \mathrm{T}$ and GRR $(P<0.05)$. Cosmolaelaps keni showed an excellent performance towards $B$. zonata eggs than other prey, due mainly to short generation time, high total egg production and intrinsic rate of natural increase. The lower performance of $C$. keni towards $C$. rodriguezi may be due to absence of certain nutrients required for predator oviposition.

Total developments of $C$. keni differed significantly among five prey insects and mites, where they were shortest on B. zonata and S. littoralis eggs and longest on C. cephalonica and $C$. rodriguez eggs. Results on the short life cycle were comparable with Cosmolaelaps vacua (Michael) on Rhizoglyphus echinopus (Fum. and Rob.) nymphs and Musca domestica L. eggs (Abou-Awad et al., 1989), and nearly twice shorter in case of C. simplex on M. javanica (Al-Rehiayani and Fouly, 2005) and C. qassimensis on M. incognita and C. rodriguez (Fouly and Abdel-Baky, 2015). Moreira et al. (2015) reported a comparable female longevity for $C$. jaboticabalensis fed F. occidentalis (57.7 days) with that of $C$. keni fed $C$. rodriguez. Much longer female longevity was mentioned by Enkegaard et al. (1997) for Hypoaspis miles (109.6 days) on T. putrescentiae, which approximately 2 times longer of the corresponding period of $C$. keni fed $C$. rodriguez.

The immature stages of $C$. keni consumed similar number of various insect eggs and nearly 26.0 individuals of $C$. rodriguez. Because of the difficulty of counting the minute eriophyid mite $A$. dioscoridis, here, we should take into account the size of various types of the tested food; one can expect that A. dioscoridis being the smallest was the easiest to capture by the predator. Abou-Awad et al. (1989) reported a higher consumption rate (more than twice) by $H$. vacua on $R$. echinopus than those of $C$. keni on $C$. rodriguez also (more than 1.5 times) on Musca domestica L. eggs versus the former on B. zonata 


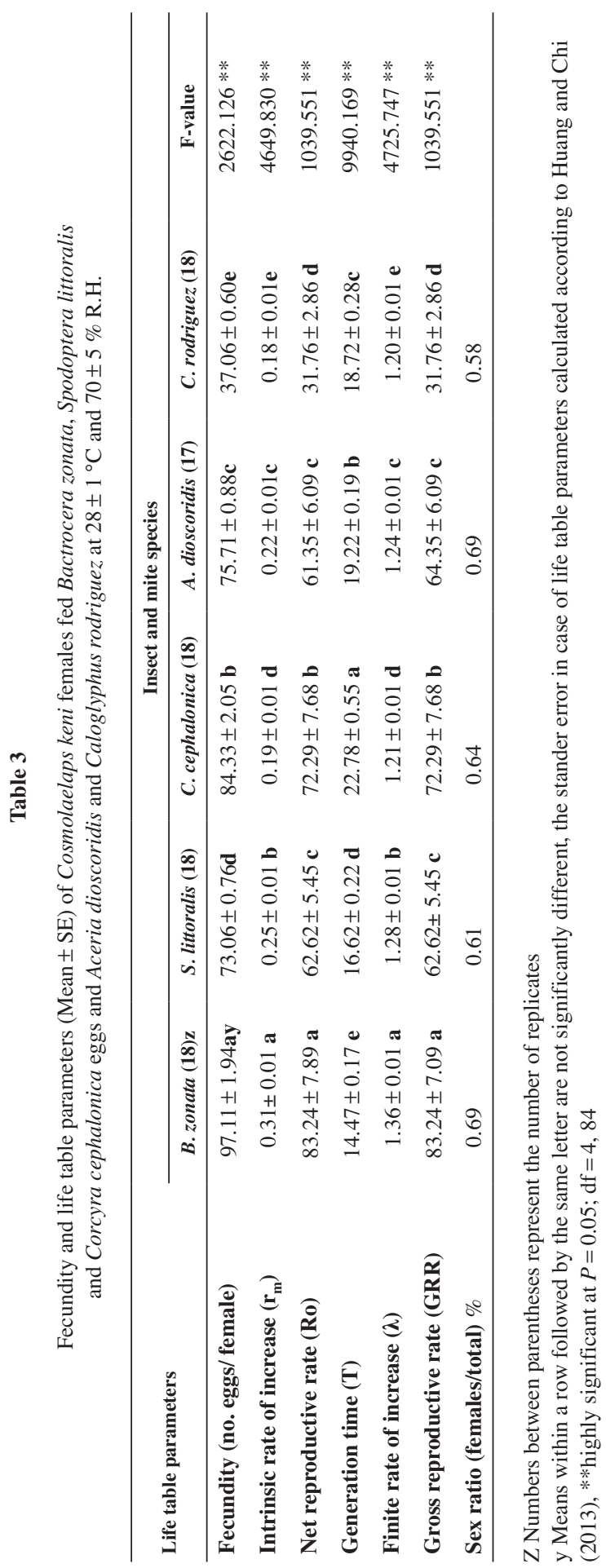


eggs. These variations could be attributed to different predators and prey studied and the environmental factors.

The present study has revealed that the mean predation rate of $C$. keni on insect eggs is considerably high, and this result supports the probability that $C$. keni is able to feed positively and reach a very high population under certain condition. Among the insects prey, $S$. littoralis eggs were more consumed by the predator than other preys, possibly because $B$. zonata or $C$. cephalonica eggs had higher biomass compared with the other one, which could be clarified $C$. keni need to feed on a greater number of $S$. littoralis eggs to get the same amount of nutrients. The oviposition rate of $C$. keni on B. zonata eggs was higher than that of $C$. jaboticabalensis on $F$. occidentalis (natural food) (Moreira et al. 2015), while Stratiolaelaps scimitus (Berlese) on the acarids Aleuroglyphus ovatus (Tropeau) and T. putrescentiae (Barbosa and de Moraes, 2016) being superior to that of C. keni on C. rodriguez.

The life table parameters, especially intrinsic and finite rates of increase reflect the nutritional value of a diet under specific conditions. Southwood (1978) indicated that the intrinsic rate of natural increase is an important parameter, describing the growth potential of a population under climatic and food conditions, because it reflects the overall effects of temperature and food on development, reproduction and survival characteristics of the population.

The significant differences in our rm and Ro values showed extensive variation among prey types in terms of suitability for C. keni.

The relatively high rates of increase resulting in a short doubling time show that $B$. zonata eggs are of good nutritional value to $C$. keni compared with other tested prey. In our study, the intrinsic and finite rates of increase and net reproductive rate are higher than that of $C$. jaboticabalensis and $C$. qassimensis on $T$. puterscentiae (Moreira et al., 2015; Fouly and Abdel-Baky, 2015), C. simpex on C. rodriguezi (Al-Rehiayani and Fouly, 2005). This difference may be due to the food types and different predators studied.

In the present study, the rapid developmental rate, short generation time and higher fecundity and net reproductive rates of $C$. keni were on B. zonata eggs. Consequently, B. zonata can be easily and inexpensively reared (Momen et al., 2016) and that could be a good candidate as a factitious prey for rearing $C$. keni and support its population in augmentative release programs. According to Nguyen et al. (2014) food nutritional deficiencies may only show after several generations of rearing. Therefore, further research will have to be done in order to draw meaningful conclusions regarding the suitability of the food types tested in the present study to sustain oviposition and development of $C$. keni over several generations.

\section{Conclusion}

In conclusion, the results of the present study indicate the possibility of using some insect eggs as factitious foods for mass-rearing of $C$. keni, potentially reducing production costs and fostering wider use of this biological control agent. Eggs of B. zonata proved to be an excellent prey and of high nutritional value for $C$. keni mass rearing. 


\section{Acknowledgment}

Our thanks due to Professor Hsin Chi, Department of Production and Technologies, Faculty of Agricultural Science and Technologies, Nigde University, Nigde, Turkey, for his construction the Age-Stage, Two-Sex Life Table Analysis.

\section{Literature}

Abou-Awad, B. A., Nasr, A. K., Gomaa, E. A. and Abou-Elela, M. M. (1989): Feeding, development and reproduction of the predatory mite, Hypoaspis vacua on various kinds of food substances (Acari: Laelapidae). Insect Sci. Applic. 10, 503-506.

Al-Rehiayani, S. M. and Fouly, A. H. (2005): Cosmolaelaps simplex (Berlese), a polyphagous predatory mites feeding on root-knot nematode Meloidogyne javanica and citrus nematode Tylenchulus semipenetrans. Pak. J. Biol. Sci. 8, 168-174.

Barbosa, M. F. C. and de Moraes, G. J. (2016): Potential of astigmatid mites (Acari: Astigmatina) as prey for rearing edaphic predatory mites of the family Laelapidae and Rhodacaridae (Acari: Mesostigmata). Exp. Appl. Acarol. 69, 289-296.

Beaulieu, F. (2009): Review of the mite genus Gaoelaelaps Evans and Till (Acari: Laelapidae), and description of a new species from North America, G. gillespiei n. sp. Zootaxa 2158, 33-49.

Birch, L. C. (1948): The intrinsic rate of natural increase of an insect population. J. Anim. Ecol. 17, 15-26.

Castilho, R. C., de Moraes, G. J., Silva, E. S. and Silva, L. O. (2009): Predation potential and biology of Protogamasellopsis posnaniensis Wiśniewski and Hirschmann (Acari: Rhodacaridae). Biol. Cont. 48,164-167.

De Clercq, P., Merlevede, F. and Tirry, L. (1998): Unnatural prey and artificial diets for rearing Podisus maculiventris (Heteroptera: Pentatomidae). Biol. Cont. 12,137-142.

Enkegaard, A., Sardar, M. A. and Brødsgaard, H. F. (1997): The predatory mite Hypoaspis miles: biological and demographic characteristics on two prey species, the mushroom sciarid fly, Lycoriella solani, and the mould mite, Tyrophagus putrescentiae. Ent. Exp. Appl. 82, 135-146.

Fouly, A. H. and Abdel-Baky, N. F. (2015): Influence of prey types on the biological characteristics of of Cosmolaelaps qassimensis (Acari: Laelapidae). J. Entomol. 12, 21-29.

Grenier, S. and De Clercq, P. (2003): Comparison of artificially versus naturally reared natural enemies and their potential for use in biological control. In: J. van Lenteren (ed.): Quality Control and Production of Biological Control Agents: Theory and Testing Procedures. CABI Publishing, Wallingford, pp 115-131.

Huang, Y. B. and Chi, H. (2013): Life tables of Bactrocera cucurbitae (Diptera: Tephritidae): with an invalidation of the Jackknife technique. J. Appl. Entomol. 137, 327-339.

Massaro, M., Ignez Martin, J. P. and de Moraes, G. J. (2016): Factitious food for mass production of predaceous phytoseiid mites (Acari: Phytoseiidae) commonly found in Brazil. Exp. Appl. Acarol. 70, 411-420.

Momen, F. M. and El-Laithy, A. (2007): Suitability of the flour moth Ephestia kuehniella (Lepidoptera: Pyralidae) for three predatory phytoseiid mites (Acari: Phytoseiidae) in Egypt. Int. J. Trop. Ins. Sci. 27, 102-107.

Momen, F. M., Abou-Elella, M. M., Metwally, A. M., Nasr, A. K. and Saleh, K. M. (2011): Biology and feeding habits of the predacious mite, Lasioseius lindquisti (Acari: Ascidae) from Egypt. Acta Phytopathol. et Entomol. Hung. 46, 151-163.

Momen, F. M., Metwally, A. M., Nasr, A. K., Abdallah, A. A. and Saleh, K. M. (2014): Life history of Proprioseiopsis badri feeding on four eriophyid mite species (Acari: Phytoseiidae and Eriophyidae). Phytoparasitica 42, 23-30.

Momen, F. M., Nasr, A. K., Metwally, A. M., Mahmoud, Y. A. and Saleh K. M. (2016): Performance of five species of phytoseiid mites (Acari: Phytoseiidae) on Bactrocera zonata eggs (Diptera: Tephritidae) as a factitious food. Acta Phytopathol. et Entomol. Hung. 51, 123-132.

Moreira, G. F., de Morais, M. R., Busoli, A. C. and de Moraes, G. J. (2015): Life cycle of Cosmolaelaps jaboticabalensis (Acari: Mesostigmata: Laelapidae) on Frankliniella occidentalis (Thysanoptera: Thripidae) and two factitious food sources. Exp. Appl. Acarol. 65, 219-236.

Nasr, A. K., Momen, F. M., Metwally, A. M., Gesraha, M., Abdallah, A. A. and Saleh, K. M. (2015): Suitability of Corcyra cephalonica eggs (Lepidoptera: Pyralidae) for the development, reproduction and survival of four predatory mites of the family Phytoseiidae (Acari: Phytoseiidae). Ges. Pfl. 67, 175-181. 
Navarro-Campos, C., Wackers, F. L. and Pekas, A. (2016): Impact of factitious foods and prey on the oviposition of the predatory mites Gaeolaelaps aculeifer and Stratiolaelaps scimitus (Acari: Laelapidae). Exp. Appl. Acarol. 70, 69-78.

Nguyen, D. T., Vangansbeke, D. and De Clereq P. (2014): Artificial and factitious foods support the development and reproduction of the predatory mite Amblyseius swirski. Exp. Appl. Acarol. 62, 181-194.

Riddick, E. W. (2009). Benefits and limitations of factitious prey and artificial diets on life parameters of predatory beetles, bugs, and lacewings: a mini-review. BioControl 54, 325-339.

Southwood, T. R. E. (1978): Ecological Methods. Chapman and Hall, New York, NY, 388-406.

Vangansbeke, D., Nguyen, D. T., Audenaert, J., Verhoeven, R., Gobin, B., Tirry, I. and De-Clercq, P. (2014): Performance of the predatory mite Amblydromalus limonicus on factitious foods. BioControl 59, 67-77.

van Lenteren, J. C. (2003): Commercial availability of biological control agents. In: D. E. Walter and H. C. Proctor (eds): (1999): Mites: Ecology, Evolution and Behaviour. CABI Publishing, Wallingford, Chapter $11,167 \mathrm{p}$.

Walter, D. E. and Proctor, H. C. (1999): Mites: Ecology, Evolution and Behaviour. CABI Publishing, Wallingford, $352 \mathrm{p}$.

Zhang, Z. Q. (2003): Mites of Greenhouses: Identification, Biology and Control. CABI Publishing, Wallingford, $244 \mathrm{p}$. 
